\title{
Therapeutic Evaluvation of Patients with Alopecia Areata.
}

\author{
Lakshmi Radhakrishnan ${ }^{1}$, Karunakaranmaduravasagam $^{2}$, \\ KarpagamBaliah ${ }^{3}$,JayasriJambulingam ${ }^{4}$ \\ ${ }^{I}$ Senior Resident, Department Of Dermatology, Tiruvannamalai Medical College, Tiruvannamalai. \\ ${ }^{2}$ Professor,Department Ofdermatology, Tiruvannamalai Medical College, Tiruvannamalai. \\ ${ }^{3}$ Assistant Professor, Department Ofdermatology, Tiruvannamalai Medical College, Tiruvannamalai. \\ ${ }^{4}$ seniorresident, Department Ofdermatology, Tiruvannamalai Medical College, Tiruvannamalai.
}

\begin{abstract}
Introduction: Alopecia Areata (AA) is a non - scarring inflammatory hair loss disease that can affect men, women and children. Though multiple modality of treatment are available, topical therapy is preferable in view of fewer side effects, Hence this study was carried out to see the responses of two topicalmodalities of therapy.

Materials And Methods:- Patients presenting with AA, to our dermatology department during the month of june 2016 were recruited.The two topical modalities were tried and results were analysed at the end of 3 month study period. (July, August, September) 2016.

Results And Conclusion:- Acceptable regrowth of hair was seen in equal number of patients treated with Betasalic ointment and 5\% minoxidil. The two modalities may be considered in the therapy of alopecia areata as the adverse effect was noticed was transient.
\end{abstract}

\section{Introduction}

ALOPECIA AREATA (AA) (Abbreviation: AA-Alpeciaareata) is a non scarring, inflammatory hair loss disease that can affect men, women and children. It produces marked cosmetic disability and extensive psychological morbidity. Though multiple modalities of treatment are available, topical therapy is preferable in view of fewer side effects. Hence this study was carried out to see the responses of a few topical modalities of therapy.Hair is a cutaneous appendage typical of mammalian skin ${ }^{1}$. It has no vital function in humans, but its psychological functions are extremely important ${ }^{2}$. Hair is present all over the body except over the palmoplantar skin, mucocutaneous junction and the distal dorsal parts of digits ${ }^{1}$. In the scalp of adults aged $20-30$ years the density of hair on an average is $615 / \mathrm{cm}^{2}$ and this density gradually decreases to $435 / \mathrm{cm}^{2}$ by $80-90$ years of age . Alopecia areata may be defined as an unpredictable usually patchy non-scarring hair loss condition ${ }^{3}$. Any hair bearing area be affectedby AA.

AA accounts for about $2 \%$ of mew dermatological outpatient attendance ${ }^{2,4}$.Various theories such as infectious, genetic, stress, trauma (physical), immunologic, endocrine dysfunction and focal sepsis have been postulated.

\section{Prognosis}

The prognosis is good in the common simple form of AA in which the hair loss is confined to the scalp and has got a high natural remission rate.

\section{Treatment}

Early recognition, intervention involving topical and or intralesional therapy and education can provide patient with comforting reassurance about eventual recovery.

\section{Topical Therapies Include ${ }^{78}$}

1 Non specific irritants- Phenol,Salicylic acid, Sulphur. Dithranol, Liquid nitrogen, cantharides etc.

2 Contact sensitisers- Dinitrochlorobenzene, Squaric acid dibutyl ester (SADBE)and diphencyprone ${ }^{5}$

3 Topical steroids

4 Other topical modalities include- Topical PUVA, Topical minoxidil, Topical tacrolimus,Imiquimod

\section{Systemic Therapy Includes}

1 Systemic steroids

2 Immunomodulators like cyclosporine, systemicpsoralen,inosiplex (Isoprinosine), etc.

\section{Miscellaneous Modalities Include}

1 Intralesional steroids

2 Irradiation 
3 Psychotherapy

4 Wig.

\section{Aims Of Study}

The aims of the present study was

1. To study the efficacy of two modalities of topical treatment and to compare them with one another.

2. To study the adverse effects of the topical modalities used.

3. The topical therapies used in the present study were

(i) Topical use of an ointment containing $0.05 \%$ Betamethasone and 3\% Salicyclic acid.

(ii) Topical applicatiom of 5\% Minoxidil solution.

\section{Materials And Methods}

Patients presenting with AA to the dermatology department of our hospital during the month of june 2016 were recruited for the study. A thorough history was elicited with regards to the duration of symptoms, progression of the disease, history of past episodes, history of any treatment both topical and systemic therapy, history suggestive of any psychiatric disturbances and septic foci.A personal and family history of atopy, other dermatoses, diabetes mellitus and hypertension and history suggestive of any other autoimmune disease were also elicited. A meticulous general and systemic examination was performed. A dental and ENT opinion was sought to rule out septic foci. A complete haemogram was carried out in all the patients and a random blood sugar in adults was done. The individuals with history of exposure to the risk of STD were subjected to a blood VDRL examination. After completing the examinations 20 patient were registered having only scalp involvement. Patients who had no treatment either topical or systemic in the past 3 months. Before starting the therapy appropriate treatment of focal sepsis if any were given to patients. The patients were divided into 2 groups comprising 10 in each group and the following therapy was instituted. The study period was 3 months (July, August, September)

\section{Group I: Patients Submitted For Topical 0.05 Betamethasone Dipropionate With Salicylic Acid 3\%}

Alopecia areata has been frequently treated with either topical steroids or salicylic acid. Salicylic acid is an irritant and in addition when combined with steroids it enhances the penetration of steroid. ${ }^{60}$ Due to wide and easy availability of this preparation this was tried in the treatment of AA. Ten patients were treated with topical application of the ointment containing $0.05 \%$ Betamethasone dipropionate and $3 \%$ saliyclicacid. The patients were told to apply the ointment once daily until acceptable hair growth occurred or till the end of study period that is 3 months.

\section{Group Ii: Patient Treated With 5\% Minoxidil}

Ten patients were treated with $5 \%$ topical minoxidil solution. The patients were advised to apply few drops evenly over the patches not exceeding by $2 \mathrm{ml} /$ day twice daily. The patients were reviewed once in 15 days for 3 months.

During follow up the following changes were noted and recorded.

1. Increase in size of the lesions.

2. Appearance of new lesions.

3. Response to therapy was noted as follows

a. No growth of hair

b. Appearance of vellus hair

c. Growth of pigmented normal hair

d. Extent of regrowth.

4. Complication of therapy like

a. Burning and irritation

b. Erythema

c. Vesiculation

d.Pigmentary changes

e. Folliculitis

f. Atrophy etc. were recorded

\section{Observations}

An analysis of the clinical profile of the patients recruited for the therapeutic responses revealed the following data. There were 7 females and 13 males in the study groups. The age of the patients ranged from 7 years to 52 years, the average age being 25.2 years. The duration of the disease ranged from 1 week to 3 years, the average duration being 4.8 months. Two patients had a family history of atopy in the form of asthma. There was a personal history of atopy in 4 patients in form of allergic rhinitis (1), urticaria (2), pityriasisalba (1). One patient had a family h/o atopy in the form of asthma and also had pityriasis alba on the face at the time of examination. 
All patients had single episode except for one patient who had five episodes previously.The number ofpatches varied from 1 to 8 , the average being 1.8. The region wise distribution of the patches were Temporal (3), Parietal (8), Occipital (4) and Frontal (5). The nail changes noticed among the patients were pitting of the nails in 5, punctuate leuconychia in 4 , linear grooves in 2 and melanonychia in 1 patient. Two patients had hyperpigmention of the oral mucosa.

Group I: Results obtained in patient treated with $0.05 \%$ betamethasone dipropionate and $3 \%$ salicylic acid were as follows.

Acceptable regrowth of hair occurred in 5 out of 10 patients in this group excellent response was seen in 3 patients, good response in 1, moderate response (Fig.5,6) in 1, poor response in 3 patients and very poor response (Fig.7,8)in 2 patients (Table 2 ).

In all the 3 three patients with excellent response, regrowth started after 2 weeks and in one of them it was complete by 10 weeks. In patients with good and moderate response regrowth started at 4 weeks. In patients with poor and very poor response regrowth started only at 8 weeks. In one patient with Oophiasic type there was very poor response. In this group none of the patients developed new lesions or extension of the existing lesions during the study period. No adverse effects to the therapy were noticed on observation or reported by the patient during the study period.

Group Ii: Results obtained by the patient treated with 5\% minoxidil were as follows

Acceptable regrowth of hair occurred in 9 out of 10 patients in this group excellent response (Fig.9,10,11,12) was seen in 4 patients, good response in 3, moderate response 2 and very poor response in 1 (Table 3)

The hair regrowth in patients with excellent response was noticed at the end of 2 weeks in 3 patients, and 4 weeks in one of them and complete hair regrowth was noticed only at the end of 12 weeks. In one of the patients there was increase in size of the patch (Fig.10) during therapy but the hair regrowth was complete (Fig.12). In patients with good response, the patients started regrowing hair at the between 4 and 8 weeks. In one of the patients with moderate response, though the patch showed complete growth of hair, the patches continued to increase in size at the margins whereas in the other two patients regrowth was noticed at 8 weeks. The patients with very poor response did not show any evidence of hair regrowth.

None of the patients complained of any adverse effects to the drugs nor were any signs of irritation noticed during the follow up period.

Responses to various modalities of therapy has been summarized as follows.

Table 5: Table Showing Responses To Topical Therapies

\begin{tabular}{|l|l|l|l|}
\hline Response & Excellent & $\begin{array}{l}\text { Good and } \\
\text { Moderate }\end{array}$ & $\begin{array}{l}\text { Poor \& } \\
\text { V.Poor }\end{array}$ \\
\hline Betamethasone & 3 & 3 & 4 \\
\hline Minoxidil & 4 & 5 & 1 \\
\hline
\end{tabular}

Response of single and multiple patches to various modalities of topical therapy is given below

Table 6: Response Of Single And Multiple Patches To Topical Therapy

\begin{tabular}{|l|c|c|c|}
\hline \multicolumn{1}{|c|}{ Single Patch } & Excellent & $\begin{array}{c}\text { Good \& } \\
\text { Moderate }\end{array}$ & $\begin{array}{c}\text { Por\& } \\
\text { V.Poor }\end{array}$ \\
\hline Betamethasone & 1 & 1 & 1 \\
\hline Minoxidil & 4 & 5 & 1 \\
\hline Multiple Patch & Exellent & $\begin{array}{c}\text { Good \& } \\
\text { Moderate }\end{array}$ & $\begin{array}{c}\text { Poor \& } \\
\text { V.Poor }\end{array}$ \\
\hline Betamethasone & 2 & 2 & 3 \\
\hline Minoxidil & 0 & 0 & 0 \\
\hline
\end{tabular}

Therapeutic responses in patients with personal and family history to atopy compared to other normal individuals is given in the table below.

Table 7: Therapeutic Response In Atopics Vs.Non Atopics

\begin{tabular}{|c|c|c|c|}
\hline Atopic & Excellent & $\begin{array}{c}\text { Good \& } \\
\text { Moderate }\end{array}$ & $\begin{array}{c}\text { Poor \& V. } \\
\text { Poor }\end{array}$ \\
\hline Single Patch & 1 & 4 & 1 \\
\hline Multiple Patch & 0 & 1 & 1 \\
\hline Total & 1 & 5 & 2 \\
\hline Non Atopic & Exellent & $\begin{array}{c}\text { Good \& } \\
\text { Moderate }\end{array}$ & $\begin{array}{c}\text { Poor \& V. } \\
\text { Poor }\end{array}$ \\
\hline Single Patch & 8 & 6 & 6 \\
\hline Multiple Patch & 5 & 3 & 4 \\
\hline
\end{tabular}




\begin{tabular}{|l|l|l|l|} 
Total & 13 & 9 & 10 \\
\hline
\end{tabular}

3 of the 4 (75\%) patients with atopy showed acceptable regrowth of hair and 33 of the $40(60 \%)$ patients without personal or family history of atopy showed acceptable regrowth of hair.

\section{Conclusion}

1. Atopy in the form of personal and family history was the only significant association found in the present study group. (in 20\% of patients)

2. Acceptable regrowth of hair was seen in patients treated with $5 \%$ topical minoxidil and Betasalic ointment.

3. The Two modalities may be considered in the therapy of alopecia areata as the adverse effect noticed was transient.

4. Atopy does not appear to be a significant factor in the response to therapy in patients with alopecia areata.

\section{References}

[1]. Wadhwa SL, Khopkar U. Hair and Scalp disorders. In: Valia RG ED. IADVL Textbook and Atlas of Dermatology. $2^{\text {nd }}$ ed. Bhalani Publishing House, 2001: 1: 733- 737.

[2]. Dawber RPR, Berker Ode, Wgnarowska F. Disorders of hair, In: Champion RH, Burton JL. Burns DA. et al, eds. Textbook of Dermatology. $6^{\text {th }}$ ed. Oxford, England: Blackwell Science, 1998: 3: 2919- 2927.

[3]. Madani S. and Shapiro J. Alopecia areata an update. J Am Acad ofDermatol 2000; 42: 549 - 565.

[4]. Wilma FB. Hair disorders. In: Moschella and Hurley eds. Textbook of dermatology, $3^{\text {rd }}$ ed. Saunders 2: 1545-6.

[5]. Elsie AO. Hair disorders. In: Freedberg IM, Eisen AZ, Wolff K, et al. Fitzpatricks Dermatology in General Medicine, McGraw Hill, $5^{\text {th }}$ ed. 1: $737-9$.

[6]. Fiedler VC. Potential mechanisms of minoxidil induced hair growth in alopecia areata. J Am AcadDermatol 1987; $16: 653$ - 8.

[7]. Srinivas CR, Satish PB, Ravikumar BC. Principles o Topical therapy in dermatology. In: ValiaRG Ed. IADVL Textbook and Atlas of Dermatology. $2^{\text {nd }}$ ed. Bhalani Publishing House, 2001: 2: 1254 - 5.

[8]. Shapiro J., Price V. Hair regrowth: Therapeutic agents. Dermatol Clinic 1998; 16: 341 - 56. 